\title{
A ESTRUTURAÇÃO DE REDES MULTI-STAKEHOLDERS PARA A SOLUÇÃO DE PROBLEMAS SOCIAIS COMPLEXOS
}

\author{
Roselaine Nunes de Oliveira Moscofian \\ Bacharel em Administração \\ Universidade do Vale do Rio dos Sinos (UNISINOS) \\ São Leopoldo - Rio Grande do Sul - Brasil \\ roselainenoliveira@hotmail.com \\ Douglas Wegner \\ Doutor em Administração \\ Universidade do Vale do Rio dos Sinos (UNISINOS) \\ São Leopoldo - Rio Grande do Sul - Brasil \\ dwegner@unisinos.br \\ Tatiane Pellin Cislaghi \\ Doutoranda em Administração \\ Instituto Federal de Educação, Ciência e Tecnologia do Rio Grande do Sul \\ Bento Gonçalves - Rio Grande do Sul - Brasil \\ Universidade do Vale do Rio dos Sinos (UNISINOS) \\ São Leopoldo - Rio Grande do Sul - Brasil \\ tatiane.cislaghi@bento.ifrs.edu.br
}

\section{RESUMO}

Os problemas ambientais e de saúde, causados pelo uso indevido dos agrotóxicos na agricultura familiar, vêm sendo discutidos em âmbito nacional e internacional. Nesse sentido, a pesquisa teve como objetivo propor uma rede multi-stakeholder que possa minimizar esse problema complexo que afeta a sociedade. A pesquisa empírica foi realizada em duas etapas, com abordagem qualitativa. A primeira, de natureza descritiva, consistiu em um estudo de caso de uma rede de stakeholders criada para minimizar um problema social relacionado à gestão de uma bacia hidrográfica. Esse modelo de rede serviu de inspiração para a segunda etapa da pesquisa, que consistiu na proposição de uma nova rede colaborativa capaz de minimizar os impactos do uso dos agrotóxicos. A principal contribuição da pesquisa está na proposição de um modelo de rede, identificando os stakeholders participantes e a forma de governança, cuja implementação tem o potencial de minimizar o problema dos agrotóxicos na agricultura familiar. A contribuição teórica do estudo está em descrever a estruturação de redes multi-stakeholders relacionadas a contextos que possuem complexidade social, ambiental e política.

Palavras-chave: Agricultura familiar; Agrotóxicos; Governança; Multi-stakeholders; Redes colaborativas.

\section{STRUCTURING OF MULTI-STAKEHOLDERS NETWORKS FOR THE SOLUTION OF COMPLEX SOCIAL PROBLEMS}

\section{ABSTRACT}

Environmental and health problems caused by improper use of pesticides in family farming have been receiving increasing attention at local and global levels. In this regard, this research aimed to propose a multi-stakeholder network to minimize this complex problem that affects society. The empirical research was conducted in two phases with qualitative approach. The first phase consisted in a qualitative case study that describes a multi-stakeholder network created to minimize a social problem related to the management of a watershed. This multi-stakeholder network was used as inspiration for the second phase, in which we propose a new collaborative network, to minimize the impacts of the improper use of pesticides. Our major contribution consists in the presentation of a framework that describes the stakeholders, their interaction and the governance of a network that may reduce the problem of pesticides used in family farming. As a theoretical contribution, the study describes the structuring process of a multi-stakeholders network operating in a complex social environmental and political context.

Key words: Collaborative network; Family farming; Governance; Multi-stakeholder; Pesticides. 


\section{INTRODUÇÃO}

A solução de problemas sociais complexos exige novas abordagens do poder público e dos stakeholders interessados. A complexidade das questões sociais, ambientais e políticas em pauta nos debates em nível nacional e global demonstra a necessidade de encontrar soluções por meio de iniciativas e políticas que envolvam a coletividade (Carneiro, Augusto, Rigotto, Friedrich \& Búrigo, 2015). Problemas relacionados ao saneamento básico, à contaminação das águas e do solo, ao descarte indevido do lixo, ao uso indevido dos agrotóxicos, às novas epidemias, são agravados pela falta de informação e articulação de medidas preventivas e corretivas. A complexidade do tema exige a atuação de parcerias multissetoriais, coordenadas na tentativa de minimizá-los ou solucionálos (Caporal, Costabeber \& Paulus, 2005).

Dentre as questões mencionadas, o uso inadequado de agrotóxicos, em especial na agricultura familiar, caracteriza-se como um problema grave e com sérias consequências. $\mathrm{O}$ primeiro impacto do uso destes produtos é sobre os trabalhadores que realizam as aplicações de agrotóxicos; o segundo é na população, que é atingida pela contaminação dos alimentos; e o terceiro impacto é ao meio ambiente, pela contaminação do solo, das águas e do ar (Carneiro et al., 2015). Além disso, o agricultor utiliza o agrotóxico como medida preventiva contra infestações e não como ação corretiva, provocando problemas de saúde que perpassam a contaminação do alimento (Geremia, 2011). De acordo com o dossiê da Associação Brasileira de Saúde Coletiva (Abrasco), os produtores brasileiros estão entre os que mais utilizam agrotóxicos no mundo (Carneiro et al., 2015).

A solução para problemas complexos, que afetam múltiplos atores, tal como o uso inadequado de agrotóxicos, pode estar no envolvimento destes mesmos em redes (Jacobi, 2008; Roloff, 2008). Jacobi (2008) identifica a necessidade de envolver outros setores na elaboração e implementação de políticas públicas e considera a governança realizada com a participação, envolvimento e negociação de multi-stakeholders como forma de legitimar as decisões tomadas por eles.

Diversos estudos no contexto nacional (Calixto, 2009; Harrison, Freeman \& Abreu, 2015; Neutzling, Santos, Barcellos \& Land, 2015) e internacional (Alvarez, Pilbeam \& Wilding, 2010; Airike, Rotter \& Mark-Herbert, 2016; Kilelu, Klerkx \& Leeuwis, 2013, Rolof, 2008) têm abordado as possibilidades de organizar redes de multi-stakeholders. Entretanto, há uma carência de estudos que analisam como tais redes podem ser constituídas e como organizar sua governança para alcançar os objetivos dos múltiplos participantes envolvidos (Klijn, 2014; Harrison et al., 2015; Sandfort \& Milward, 2014).

Com base nessa contextualização, a questão que norteia o estudo é: como estruturar uma rede de multi-stakeholders para a solução de um problema social complexo - o uso inadequado de agrotóxicos na agricultura familiar - e estabelecer seu modelo de governança? Para responder a esta pergunta, o estudo teve como objetivos (a) mapear uma rede existente, com vistas a compreender sua composição, modelo de governança e barreiras enfrentadas pelos atores, para então (b) propor a criação e organização de uma rede multi-stakeholder visando minimizar o uso inadequado de agrotóxicos na agricultura familiar. Nesse sentido, a pesquisa faz uso do conceito de redes multistakeholder (Roloff, 2008) e utiliza a abordagem teórica da Teoria dos Stakeholders, que é multifacetada e oferece a oportunidade de reinterpretar situações a partir de uma variedade de novas perspectivas, que envolvem simultaneamente múltiplos atores (Harrison et al., 2015).

A rede estudada como etapa preliminar exploratória, foi criada para o gerenciamento da bacia hidrográfica do Rio dos Sinos, no estado do Rio Grande do Sul. A escolha da rede se justifica pela complexidade do problema social envolvido, os interesses múltiplos e conflitantes de seus atores (setores produtivos, comunidade, Ministério Público, universidades, Organizações NãoGovernamentais (ONGs), órgãos governamentais, entidades de apoio setoriais, entre outros) e por tratar-se de uma rede com 29 anos de existência. Esse caso, por sua vez, serviu como inspiração para a segunda fase da pesquisa, em que se propõe uma nova rede multi-stakeholders, desta vez com o objetivo de minimizar o uso inadequado de agrotóxicos na agricultura familiar.

Revista de Gestão Social e Ambiental - RGSA, São Paulo, v. 12, n. 1, p. 21-37, jan./abr. 2018. 


\section{REDES MULTI-STAKEHOLDERS}

Stakeholder é definido como qualquer grupo ou indivíduo que pode afetar ou é afetado pela realização dos objetivos de uma organização (Freeman, 1984). Embora a literatura aponte variações desta definição, nessa perspectiva os stakeholders relacionam-se com uma empresa focal e existem relações dominantes de poder (Roloff, 2008). Os diálogos em que estão presentes vários grupos de atores interessados (por exemplo, consumidores, trabalhadores, sindicatos, organizações nãogovernamentais, entes políticos) e outras empresas, tais como concorrentes e fornecedores, constituem a forma mais popular de gestão dos stakeholders (Roloff, 2008).

$\mathrm{Na}$ busca de ampliar o entendimento de como as empresas que colaboram em redes multistakeholders organizam a sua gestão dos atores envolvidos, Roloff (2008) argumenta que podem existir duas abordagens: uma com foco em organizações (em benefício de uma empresa focal, ou seja, que possui o poder nas relações) e outra com a ênfase na solução de problemas. As principais diferenças nas duas abordagens estão em seu ponto de referência e no modo de interação. A gestão direcionada por uma organização focal coloca a empresa e seus objetivos no centro das atenções. Propõe proteger a empresa por meio da implementação de uma gestão de relacionamento eficaz com quem pode afetar ou é afetado por suas atividades. Em contrapartida, a gestão centrada em problemas tem como objetivo abordar uma questão que é relevante para vários atores, a fim de identificar e implementar um curso de ação compartilhado (Rollof, 2008; Scarlett e McKinney, 2016), como nessa pesquisa.

Múltiplos stakeholders ou múltiplos atores (indivíduos, unidades de trabalho ou organizações) participantes são incorporados em relações sociais interligadas em redes colaborativas, as quais oferecem ao mesmo tempo oportunidades de ganhos econômicos (Williamson, 1993) e relacionais (Dyer \& Singh, 1998). Uma rede pode ser descrita como um conjunto de nós e de laços que representam relações (Brass et al., 2004) e podem variar de acordo com a estrutura dessas relações. Considerando-se a perspectiva de governança interorganizacional (Provan \& Kenis, 2008), a rede é considerada uma unidade de análise determinante ao entendimento das interações entre as organizações (Francisco, 2011) e a vantagem colaborativa pode ser vista como um dos principais motivos para a união de atores em rede multi-stakeholders (Airike et al., 2016; Rocha \& Goldschmidt, 2010).

Nas redes multi-stakeholders, os participantes se reúnem para encontrar uma abordagem comum a uma questão (problema) que afeta a todos eles. Apesar da variedade destes modelos de redes, algumas características são compartilhadas: (a) geralmente são compostas por três categorias de atores, representantes de negócios, sociedade civil e Estado; (b) surgem ou são iniciadas a partir de um problema a ser solucionado ou minimizado; e, (c) no âmbito geográfico das redes e a dimensão das questões abordadas, podem estender-se desde redes concentradas em locais específicos até redes de abrangência global (Roloff, 2008).

Souza (2012), em seu estudo sobre redes de stakeholders, abordou o tema da participação social na gestão das políticas públicas em uma unidade de conservação ambiental. Desenvolveu uma abordagem dos conselhos gestores como plataforma multi-stakeholders para negociação de uso dos recursos naturais e considerou a participação da sociedade fundamental para a conservação da biodiversidade e proteção destas áreas. Esta estruturação possibilitou aos envolvidos a aprendizagem coletiva em diferentes níveis, destacando a troca de experiências, promoção de articulações entre atores e o fortalecimento da governança. $\mathrm{O}$ autor destacou ainda a importância do envolvimento das universidades e institutos de pesquisa.

Kilelu et al. (2013), por meio de um estudo de caso no programa de Desenvolvimento do Leite da África Oriental no Quênia, utilizaram o conceito de plataformas de inovação, usualmente aplicado no campo agrícola, a fim de desvendar como as plataformas dão forma e contribuem para os processos de inovação. O programa fornece uma plataforma para estimular a colaboração de multi-stakeholders, visando melhorar a produtividade e os rendimentos das famílias de pequenos produtores de leite. No estudo, plataforma de inovação, foi definida como uma configuração de 
múltiplos atores deliberadamente criada para facilitar e realizar diversas atividades em torno de desafios e oportunidades de inovação agrícola identificados, em diferentes níveis nos sistemas agrícolas (por exemplo, aldeia, país, setor ou cadeia de valor). Os achados da pesquisa demonstraram como as plataformas de inovação são importantes mecanismos para estimular e coordenar a coevolução da inovação. A variedade dos multi-stakeholders e a complementariedade de competências dos atores é o que tornou a plataforma efetiva na coordenação da inovação.

Apesar das pesquisas e práticas destes modelos de rede, Milagres, Rezende e Gonçalves (2012) destacam que a literatura ainda carece de clareza conceitual sobre o tema governança de redes colaborativas, existindo uma lacuna entre a compreensão dessas estruturas e como acontecem as interações entre o governo, as organizações e a sociedade civil. Dessa forma, a subseção 2.1 aborda a governança de redes, considerando-se que as redes colaborativas estão cada vez mais em destaque nas pesquisas da administração, enfatizando a crescente estruturação de parcerias entre governo e sociedade civil com o objetivo de solucionar problemas sociais complexos.

\subsection{Governança de redes}

A pesquisa sobre governança de redes foca principalmente a complexidade da tomada de decisão e os desafios para o alcance de resultados aceitáveis para problemas sociais em razão do envolvimento de múltiplos atores (Klijn, 2014). Por sua vez, as redes têm sido amplamente reconhecidas pelos estudiosos e gestores como uma importante forma de governança para multiorganizações, tanto no setor público quanto no privado (Provan \& Kenis, 2008).

Provan e Kenis (2008) propõem três formas de governança para as redes de empresas: (a) governança compartilhada: os próprios membros da rede coordenam as ações exigindo envolvimento e comprometimento de todos os partícipes; (b) governança por meio de uma organização líder: as principais atividades em nível de rede e as principais decisões são coordenadas por meio e por um único membro participante, atuando como uma organização líder. Assim, a governança da rede torna-se altamente centralizada e intermediada, com relações de poder assimétricas; e, (c) organização administrativa de rede: quando uma entidade administrativa independente externa é criada especificamente para governar a rede e as suas atividades. Ainda, os autores descrevem que a adoção bem-sucedida de uma forma particular de governança será com base em quatro contingências estruturais e relacionais principais: confiança, tamanho (número de participantes), consenso de objetivos e a natureza da tarefa (especificamente, a necessidade de competências em nível de rede).

Rezende (2014) identifica e analisa, em sua pesquisa, como a estrutura relacional da rede interorganizacional "A Cor da Cultura" influencia sua estrutura de governança. A rede é formada por entidades governamentais, privadas e pela sociedade civil e seu modelo de governança identificada é de “organização líder”, e está centrada na Fundação Roberto Marinho. Identificou que o modelo de governança compartilhada será mais eficaz quando houver confiança generalizada entre os membros e ressalta que os laços de confiança devem ser densos, de maneira que sejam compartilhados por toda a rede. No modelo de organização líder, é essencialmente construída em torno de uma "coleção de relações diádicas", caracterizada pela centralidade num grupo da rede. Neste caso, a confiança em toda a rede pode ser menor do que para a governança do modelo de organização administrativa da rede, onde os membros são chamados a monitorar coletivamente todas as atividades praticadas.

Outro exemplo é apresentado no estudo de Alvarez et al. (2010), que objetivou compreender como e porque os mecanismos de governança evoluíram em uma iniciativa multi-stakeholder na cadeia de suprimentos liderada pela Nespresso, o café especial da divisão da Nestlé. A unidade de análise foi a rede do Programa AAA, incluindo as entidades que diretamente participam dela (representantes atuais e passados, como comerciantes de café, ONGs e agricultores). Os resultados da pesquisa traçaram a evolução do contexto e condições relacionais. O contexto associado a mudanças externas (ambiente) e internas (atores específicos) evoluiu em termos de diminuição da 
incerteza e aumentou em termos de clareza no apoio a relação. Ao mesmo tempo, houve um aumento na complexidade do número e tipos de intervenientes envolvidos. Associada a esta evolução, ocorreram mudanças importantes observadas nas condições relacionais, e um aumento da formalização dos mecanismos de governança na rede.

Apesar dos resultados positivos proporcionados por redes multi-stakeholders para a solução de problemas complexos, também são identificadas dificuldades da atuação em rede. Moog et al., (2015) analisaram o Forest Stewardship Council, uma organização transnacional sem fins lucrativos formada por diversos stakeholders com o objetivo de aperfeiçoar o manejo florestal e regular o comércio de madeira. Um problema crônico identificado nessa rede é que a perspectiva de stakeholders menos poderosos e com argumentos éticos mais radicais tende a ser sufocada. Isso torna questionável se redes multi-stakeholders realmente representam um espaço real para deliberação política ou acabam sendo direcionadas pelos interesses de grupos dominantes. Os autores concluem que a dimensão política das redes precisa ser analisada para que seja efetivamente possível compreender seu funcionamento e seus resultados.

Saffer et al., (2018) também lançam novas luzes sobre os desafios da governança de redes multi-stakeholders. Embora conceitualmente essas redes sejam caracterizadas como formas igualitárias de engajamento dos atores, formas sutis de poder são manifestadas por meio dos padrões de comunicação e interação dos participantes. Os autores analisaram a Sustainable Sanitation Alliance (SuSanA), uma rede internacional formada por 217 parceiros com o objetivo de contribuir para a meta de tratamento sanitário da Organização das Nações Unidas. Os resultados revelam que o status institucional e os recursos financeiros, técnicos e relacionais aportados pelos parceiros afetam diretamente a dinâmica do poder em redes multi-stakeholders. Como consequência, os autores destacam a importância de analisar previamente o poder dos atores que serão incorporados à rede para evitar que "[...] a agenda de organizações com mais recursos possa se tornar dominante em uma rede" (Saffer et al., 2018, p. 135).

Os resultados apresentados por esses estudos (Rezende, 2014; Alvarez et al., 2010; Moog et al., 2015; Saffer et al., 2018) destacam o potencial das redes multi-stakeholders para a solução de problemas sociais complexos, mas também indicam as dificuldades e os desafios que essas iniciativas enfrentam. A literatura revisada serve como base para o estudo empírico apresentado nas próximas seções e a proposição de uma rede com o objetivo de minimizar um problema social.

\section{PROCEDIMENTOS METODOLÓGICOS}

Para alcançar o objetivo proposto, realizou-se uma pesquisa de natureza qualitativa e descritiva em duas etapas. A primeira etapa consistiu em um estudo de caso de uma rede de multistakeholders, com a finalidade de identificar os atores participantes e o modelo de governança utilizado, além de dificuldades e principais desafios enfrentados pelos múltiplos atores. Essa fase serviu como base para que, após análise dos dados, fosse estruturada e validada uma proposta de uma rede de multi-stakeholders, para o contexto do agronegócio, com o objetivo principal de auxiliar na solução de um problema complexo que afeta os ecossistemas e a sociedade - o uso inadequado de agrotóxicos na agricultura familiar.

\subsection{Etapa 1: Estudo de caso}

O estudo de caso único (Yin, 2015) utilizou, como unidade de análise, o Comitesinos (2016). A rede foi formada há 29 anos para o gerenciamento da bacia hidrográfica do Rio dos Sinos, no estado do Rio Grande do Sul. A rede foi avaliada de acordo com alguns critérios: formação da rede (atores, papéis e responsabilidades) e o seu modelo de governança, além das principais dificuldades enfrentadas e resultados obtidos desde sua criação até o ano de 2016.

As técnicas de coleta de dados utilizadas foram: (a) dados do sítio da rede (Regimento Interno e atas das assembleias do período de 14 de março de 2013 a 11 de agosto de 2016), revistas, 
folders e jornais, (b) observação não-participante na assembleia do Comitesinos realizada no dia 11 de agosto de 2016 e entrevistas semiestruturadas com 11 representantes de diferentes categorias do comitê (figura 1), no período de 20 de julho a 19 de setembro de 2016, totalizando 9h27min. A seleção dos entrevistados foi realizada considerando-se categorias definidas a priori: poder de negociação de cada stakeholder com o Comitê, a legitimidade - no seu relacionamento com o Comitê e a urgência que o Comitê concede a cada um deles no atendimento de suas necessidades (Lopes, 2015).

\begin{tabular}{|c|c|c|c|}
\hline & Categoria & ENTIDADE & Código \\
\hline \multirow{5}{*}{ 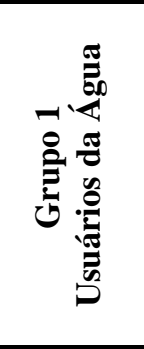 } & ABASTECIMENTO PÚBLICO & $\begin{array}{c}\text { Semae - Serviço Municipal de Água e } \\
\text { Esgotos de São Leopoldo - RS }\end{array}$ & E1UA \\
\hline & $\begin{array}{l}\text { ESGOTAMENTO SANITARIO E } \\
\text { RESÍDUOS SÓLIDOS }\end{array}$ & $\begin{array}{c}\text { Meio Ambiente da Prefeitura } \\
\text { de Portão }\end{array}$ & E2UA \\
\hline & DRENAGEM & Defesa Civil de Portão & E3UA \\
\hline & PRODUÇÃO RURAL & Associação dos Arrozeiros de Caraá & E4UA \\
\hline & INDÚSTRIA & $\begin{array}{l}\text {-Aicsul - Associação das Indústrias de } \\
\text { Curtume do RS }\end{array}$ & E5UA \\
\hline \multirow{4}{*}{ 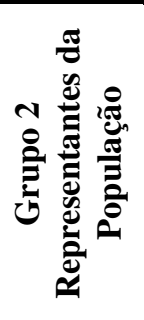 } & \multirow{2}{*}{$\begin{array}{l}\text { INSTITUIÇÕES DE ENSINO, } \\
\text { PESQUISA E EXTENSÃO }\end{array}$} & $\begin{array}{l}\text { Unisinos - Universidade do Vale do Rio } \\
\text { dos Sinos }\end{array}$ & E6RP \\
\hline & & $\begin{array}{l}\text { Instituto Senai de Tecnologia Couro e } \\
\text { Meio Ambiente }\end{array}$ & E7RP \\
\hline & ONGs AMBIENTALISTAS & $\begin{array}{c}\text { Mov. Ambientalista da Região das } \\
\text { Hortênsias }\end{array}$ & E8RP \\
\hline & ORGANIZAÇÕES SINDICAIS & Sind. dos Servidores Públicos de Portão & E9RP \\
\hline 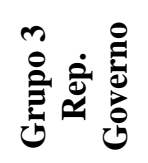 & ÓRGÃO PÚBLICO ESTADUAL & $\begin{array}{l}\text { Fundação Zoobotânica } \\
\text { FZB/Sema }\end{array}$ & E10RG \\
\hline 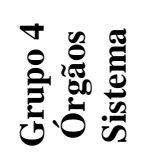 & ÓRGÃO DE FISCALIZAÇÃO & $\begin{array}{l}\text { Fepam - Fundação Estadual de Proteção } \\
\text { Ambiental Henrique Luiz Roessler }\end{array}$ & E11OS \\
\hline
\end{tabular}

Figura 1: Stakeholders entrevistados na etapa 1 da pesquisa

Fonte: Elaborado pelos autores (2018)

O roteiro de questões foi separado em quatro blocos: Bloco 1 - Formação e governança da rede com sete perguntas, Bloco 2 - Identificação dos stakeholders com cinco perguntas, Bloco 3 Dificuldades da rede com três perguntas e Bloco 4 - Resultados alcançados até 2016 com cinco perguntas. Todas as entrevistas foram gravadas e transcritas e, posteriormente, analisadas por meio da técnica de análise de conteúdo (Bardin, 2010).

\subsection{Etapa 2: Proposição e validação de uma Rede de Stakeholders}

O estudo de caso da rede do Comitesinos serviu como base para a proposição de uma nova rede direcionada para o problema social do uso indevido de agrotóxicos. O caso estudado permitiu compreender que categorias de stakeholders precisam fazer parte de uma rede para minimizar um problema social complexo, proposição de modelo de governança adequado ao contexto e quais desafios serão enfrentados na implementação da rede. Nesse sentido, elaborou-se uma proposta inicial que foi submetida à avaliação de representantes de quatro categorias, sendo: Órgão Estadual de Apoio à Agricultura (E1), Sindicato dos Trabalhadores Rurais (E2), Universidade (E3) e 
Ministério Público (E4). Estes participantes foram selecionados em razão da sua importância para a rede e pela sua capacidade de contribuir com a proposta.

Para a operacionalização desta etapa, foi apresentado a cada um dos entrevistados o desenho da rede do Comitesinos e, em seguida, o desenho da proposta da nova rede e a sua sistemática. As entrevistas foram realizadas entre 20 de outubro e 11 de novembro de 2016, totalizando $2 \mathrm{~h} 5 \mathrm{~min}$. Com base nos comentários e nas sugestões desses entrevistados, elaborou-se a proposta final da rede com o objetivo de minimizar o problema do uso indevido de agrotóxicos. Decidiu-se segmentar a rede em regiões de acordo com a divisão dos Conselhos Regionais de Desenvolvimento do Rio Grande do Sul (Coredes). Os Coredes são divididos em 27 regiões e, para a proposta da rede, optou-se primeiramente, pela Região do Vale do Caí (Corede, 2010).

\section{RESULTADOS DA PESQUISA}

Na primeira parte da seção de resultados, apresenta-se o estudo de caso do Comitesinos, com a origem da rede, os critérios de escolha e a forma de engajamento dos stakeholders, seguido pelo modelo de governança utilizado e as dificuldades da rede. Na segunda parte, é apresentada a proposta de uma rede de multi-stakeholders para minimizar o uso de agrotóxicos na agricultura familiar.

\subsection{A Rede Comitesinos}

O movimento que deu origem ao Comitesinos surgiu em 1970 da união de interesses entre grupos ambientalistas que faziam pressão para a recuperação do Rio dos Sinos, pesquisadores, imprensa e servidores do Estado, conferindo legitimidade ao movimento. Foi criado no dia 17 de março de 1988 pelo Decreto Estadual no 32.774/1988, sendo o primeiro comitê de bacia do Estado e modelo para a criação dos demais comitês do Brasil. É a rede responsável pelo gerenciamento da bacia hidrográfica do Rio dos Sinos que abrange 32 municípios.

De acordo com as entrevistas, o principal objetivo do Comitesinos é fazer a gestão das águas, garantir que haja água para o abastecimento da população e assegurar a manutenção da vida silvestre que depende desta água. Estudos técnicos de monitoramento indicam os objetivos alcançados e o que ainda falta ser feito para melhorar as condições do rio. O feedback das ações realizadas pelo comitê é disponibilizado aos membros e à sociedade durante as assembleias e também no site. As assembleias são públicas e qualquer pessoa tem direito em se manifestar e opinar sobre os assuntos em pauta.

\subsubsection{Critérios de escolha dos Stakeholders}

Em 1978, durante o seminário realizado na Sede da Unisinos, o critério utilizado para a formação do comitê foi a adesão espontânea dos participantes presentes ao evento (E11OS). Após a Lei Estadual de Recursos Hídricos no 10.350 de 1994, o comitê teve que se reestruturar para se adequar ao Regimento Interno, foi então sistematizado o comitê de bacia por divisão em categorias para que houvesse um equilíbrio entre os atores. Diante destas novas regras, aconteceram reuniões para discutir a representatividade de cada categoria e a sua importância para a bacia do Rio dos Sinos. O entrevistado E11OS cita a importância do equilíbrio entre eles, "[...] nenhum setor hegemoniza o comitê, todos têm mais ou menos o mesmo poder, e isto faz com que ele tenha sempre que negociar as coisas".

De acordo com o Regimento Interno (2016), o comitê exerce as suas atribuições diretamente ou por intermédio dos órgãos e entidades integrantes. Tem como membros as entidades ou organismos representativos dos usuários da água, da população da bacia hidrográfica e dos órgãos da administração direta, estadual e federal. A disposição das vagas para os representantes é distribuída entre três grupos principais, sendo o Grupo 1 (Usuários da água, com $40 \%$ das vagas) e 
Grupo 2 (Representantes da população, com $40 \%$ das vagas), possuem direito a voto nas plenárias. O Grupo 3 (representantes do Governo, com 20\%) faz parte da plenária, mas não tem direito a voto. O Grupo 4, que não consta no Regimento Interno, é formado por membros permanentes do plenário, não tem direito a voto e atua como órgão de fiscalização do sistema, como, por exemplo, a Fundação Estadual de Proteção Ambiental (Fepam).

Segundo os entrevistados, a posição e a importância que o Comitesinos foi adquirindo perante a sociedade ao longo dos anos de existência o tornou foco de interesse de diversas categorias que se candidatam a participar. Ou seja, a rede conquistou legitimidade, principalmente por envolver múltiplos atores nas decisões tomadas (Jacobi, 2008; Lopes, 2015). A cada dois anos, a própria categoria decide, por meio de votação, quem vai ocupar as vagas existentes para cada uma delas. Essa sistemática está alinhada com os postulados de Klijn (2014), segundo o qual a união de atores em parcerias público-privadas é necessária para que os problemas complexos de ordem pública sejam resolvidos.

\subsubsection{Governança do Comitesinos}

A governança em rede enfatiza a complexidade da tomada de decisão e os desafios para o alcance de resultados na solução de problemas sociais, contando com a participação de multistakeholders (Klijn, 2014). No Comitesinos, o plenário aprova ou reprova toda a política do comitê e fiscaliza a execução das ações. Os gestores da rede são eleitos entre os candidatos das categorias de Usuários da Água e dos Representantes da Sociedade Civil. O Presidente, o Vice-Presidente e a Secretaria Executiva formam o núcleo de gestão, "[...]que dá a direção, literalmente, do que vai ser feito" (E11OS). As ações de monitoramento da rede são realizadas em conjunto entre os diversos atores, e, desta forma, contribui para o fortalecimento das relações entre o Comitesinos, a sociedade e o governo (Roloff, 2008). Em síntese, a tomada de decisões começa pela Direção, com o auxílio da Comissão Permanente de Assessoramento (CPA), composta pela Secretária Executiva e por representantes das entidades membro.

Outro ponto de destaque citado pelos entrevistados, é a importância de o comitê estar localizado dentro da universidade. O entrevistado E1UA relata que a universidade proporciona um respaldo importante, como, por exemplo, "[...] politicamente, tu pode bater o martelo e dizer 'ah vamos fazer', e aí chega lá e diz 'ah isso aqui a universidade não vai assinar, por esse e esse motivo [...] a Unisinos é uma universidade boa, é uma universidade poderosa”.

\subsubsection{Barreiras enfrentadas pela Rede}

Entre as principais dificuldades enfrentadas pela rede, os entrevistados destacam a gestão dos conflitos. Para a maioria dos entrevistados, o Comitesinos tem a característica de uma câmara de gestão de conflitos. O Rio dos Sinos é relativamente pequeno e localiza-se em uma região com uma grande densidade populacional. Possui em seu entorno uma significativa atividade econômica e também uma área agrícola considerável para o tamanho da bacia, o que acaba gerando conflitos pelo uso dessa água. São conflitos devido à poluição causada pela população, muitas vezes sem o devido tratamento de esgotos, também citam os conflitos entre o setor agrícola, a indústria e o abastecimento urbano e também entre os arrozeiros, ecologistas e as prefeituras.

Para os entrevistados E2UA, E3UA, E6RP e E8RP, os conflitos não dificultam as ações do comitê. Comentam que ele foi criado para tentar, de alguma maneira, resolver os problemas que atingem a bacia. Para o entrevistado E7RP, estes conflitos dificultam na medida em que as pessoas não olham para a bacia como um todo, apenas para os seus interesses particulares ou de um pequeno grupo. O entrevistado E11OS relata que, antes da criação do comitê, só ocorriam situações de conflitos: "[...] os ecologistas reclamavam da poluição, os industriários diziam que os ecologistas eram contra o progresso e não havia um espaço onde houvesse diálogo, era briga". Somente após a formação do comitê, os diálogos e as negociações começaram a ocorrer. Além disso, o Ministério 
Público age como um intermediador dos acordos entre os atores. Na próxima seção, apresenta-se a proposta de uma nova rede multi-stakeholder com o objetivo de minimizar o uso inadequado de agrotóxicos na agricultura familiar no estado do Rio Grande do Sul, mais especificamente na região do Vale do Caí.

\subsection{Proposição e validação de uma rede multi-stakeholders}

O estudo de caso da rede de multi-stakeholders do Comitesinos serviu como base para a proposição de uma nova rede, direcionada para o problema social dos agrotóxicos e submetida à avaliação de representantes de quatro categorias de stakeholders: Órgão estadual de apoio à agricultura (E1), Sindicato dos trabalhadores rurais (E2), Universidade (E3) e Ministério Público (E4). Optou-se por elaborar uma proposta que, primeiramente, abrange um único Conselho Regional de Desenvolvimento do Estado do Rio Grande do Sul, denominado de Vale do Caí. Essa região é formada por dezenove municípios cuja produção de citros e morangos é a maior do estado. No entanto, o uso dos agrotóxicos é abusivo e incorreto e o destino do lixo agrotóxico não é realizado corretamente (Corede, 2010).

Sendo assim, procurou-se primeiramente identificar os stakeholders que fazem parte deste cenário, tomando como parâmetro o modelo adotado pelo Estado. Neste modelo, os segmentos do agronegócio são classificados segundo a sua posição em relação à atividade agropecuária, sendo eles: segmento antes da porteira, dentro da porteira e depois da porteira (FEE, 2016). Nas seções seguintes, serão descritos os processos para estruturação da rede por meio da representação gráfica, identificando os grupos e as categorias de stakeholders, bem como o esquema de relação entre eles.

\subsubsection{Formação da rede proposta}

Identificou-se, na primeira etapa do estudo, a importância da iniciativa da universidade para a formação do comitê. Sendo assim, propõe-se o envolvimento das universidades presentes na região para auxiliar, juntamente com órgãos do governo, ONGs, associações de consumidores, jornais da região, proporcionando assim, legitimidade ao movimento (Lopes, 2015).

O problema do uso inadequado dos agrotóxicos é discutido por diversas entidades, mas em eventos isolados, não existindo uma integração entre os envolvidos neste contexto. A formação de um comitê terá como objetivo reunir estas entidades para discutir o problema e encontrar soluções para minimizar estes impactos. Para institucionalizar o Comitê, será necessário fazer uma proposta juntamente com os órgãos do estado, municípios e representantes da sociedade legalmente constituídos e encaminhá-la ao órgão superior do governo para aprovação. A rede será dividida em seis grupos de stakeholders e suas interações estão apresentadas na subseção 4.2.2.

\subsubsection{Stakeholders da rede proposta}

Cada categoria de stakeholders elegerá seu representante no comitê. Como critérios de escolha, de acordo com a fundamentação teórica, identificou-se os atributos de "poder, legitimidade e urgência" de cada categoria, priorizando, assim, a forma de engajamento e a interação entre eles, além de classificá-los por importância. A figura 2 apresenta a divisão em grupos de acordo com atributos de cada stakeholder e as características da interação entre eles. 


\begin{tabular}{|c|c|c|}
\hline Grupos & Componentes & Características \\
\hline \multicolumn{3}{|c|}{ ATRIBUTOS: PODER, LEGITIMIDADE E URGÊNCIA } \\
\hline $\begin{array}{l}\text { Grupo } 1 \\
\text { Produção } \\
\quad \text { rural }\end{array}$ & $\begin{array}{l}\text { Emater } \\
\text { Sindicatos rurais } \\
\text { cooperativas } \\
\text { agroindústrias e } \\
\text { distribuidores } \\
\end{array}$ & $\begin{array}{l}\text { Os produtores são o foco de mudança dentro do comitê e praticamente todas } \\
\text { as ações serão desenvolvidas para este grupo. A Emater, os Sindicatos } \\
\text { Rurais e as Cooperativas serão os órgãos de divulgação e captação dos } \\
\text { produtores rurais para dentro da rede. }\end{array}$ \\
\hline $\begin{array}{c}\text { Grupo } 2 \\
\text { Empresas }\end{array}$ & $\begin{array}{l}\text { Fabricantes } \\
\text { fornecedores } \\
\text { agropecuárias } \\
\quad \text { inpEV }\end{array}$ & $\begin{array}{l}\text { O Comitê pode regulamentar a venda do agrotóxico por meio da } \\
\text { padronização do acesso a este produto. O processo inicia no distribuidor, } \\
\text { depois passa para a agropecuária e depois para o agricultor. Criar uma } \\
\text { logística para o recebimento do agrotóxico pelo agricultor e para a } \\
\text { devolução das embalagens. }\end{array}$ \\
\hline $\begin{array}{l}\text { Grupo } 3 \\
\text { Instituiçõos } \\
\text { de Ensino }\end{array}$ & $\begin{array}{l}\text { Universidades } \\
\text { escolas estaduais } \\
\text { e municipais } \\
\text { Senai } \\
\text { Emater }\end{array}$ & $\begin{array}{l}\text { A parceria com as universidades pode proporcionar o intercâmbio de } \\
\text { profissionais das áreas que contemplam o comitê. Neste sentido, vão } \\
\text { beneficiar o comitê pela capacitação dos membros do Grupo } 1 \text { e do Grupo } 2 \\
\text { e as universidades vão se beneficiar utilizando o comitê para objeto de } \\
\text { estudo. }\end{array}$ \\
\hline \multicolumn{3}{|c|}{ ATRIBUTOS: LEGITIMIDADE E URGÊNCIA } \\
\hline $\begin{array}{l}\text { Grupo } 4 \\
\text { Representant } \\
\text { es da } \\
\text { sociedade }\end{array}$ & $\begin{array}{l}\text { Associações } \\
\text { comunitárias e de } \\
\text { consumidores } \\
\text { Legislativos } \\
\text { ONGs } \\
\end{array}$ & $\begin{array}{l}\text { A responsabilidade deste grupo será de cobrar os resultados do comitê e, a } \\
\text { partir do momento que existe o Selo Produção Consciente do comitê, o } \\
\text { consumidor não comprará do agricultor que não possua este selo. Esta é } \\
\text { uma maneira de incentivar o produtor a fazer parte do comitê. }\end{array}$ \\
\hline \multicolumn{3}{|c|}{ ATRIBUTOS: PODER E LEGITIMIDADE } \\
\hline $\begin{array}{l}\text { Grupo 5 } \\
\text { Representant } \\
\text { es do } \\
\text { governo }\end{array}$ & $\begin{array}{l}\text { Secretarias } \\
\text { municipais, } \\
\text { Patram, Polícia } \\
\quad \text { Rodov. }\end{array}$ & $\begin{array}{l}\text { Este grupo participará do comitê para regulamentar as normas e fiscalizar } \\
\text { estas ações, juntamente com os órgãos de instância superior. Fazem parte, as } \\
\text { secretarias dos municípios, com competências para assessorar na elaboração } \\
\text { de propostas que visem minimizar os efeitos dos agrotóxicos na lavoura, na } \\
\text { saúde da população e ao meio ambiente. }\end{array}$ \\
\hline $\begin{array}{l}\text { Grupo } 6 \\
\text { Órgãos do } \\
\text { Sistema } \\
\end{array}$ & $\begin{array}{l}\text { Ibama, Fepam } \\
\text { Vig. Sanitária }\end{array}$ & $\begin{array}{l}\text { Este grupo irá fiscalizar as ações das entidades representantes do comitê. } \\
\text { Exemplo: Fiscalizar a venda de agrotóxicos e o uso destes produtos pelo } \\
\text { agricultor. }\end{array}$ \\
\hline
\end{tabular}

Figura 2: Identificação dos atributos e características de cada grupo

Fonte: Elaborado pelos autores (2018)

A Figura 3 representa o esquema do processo e interação dos stakeholders descritos na subseção 4.2.2. 


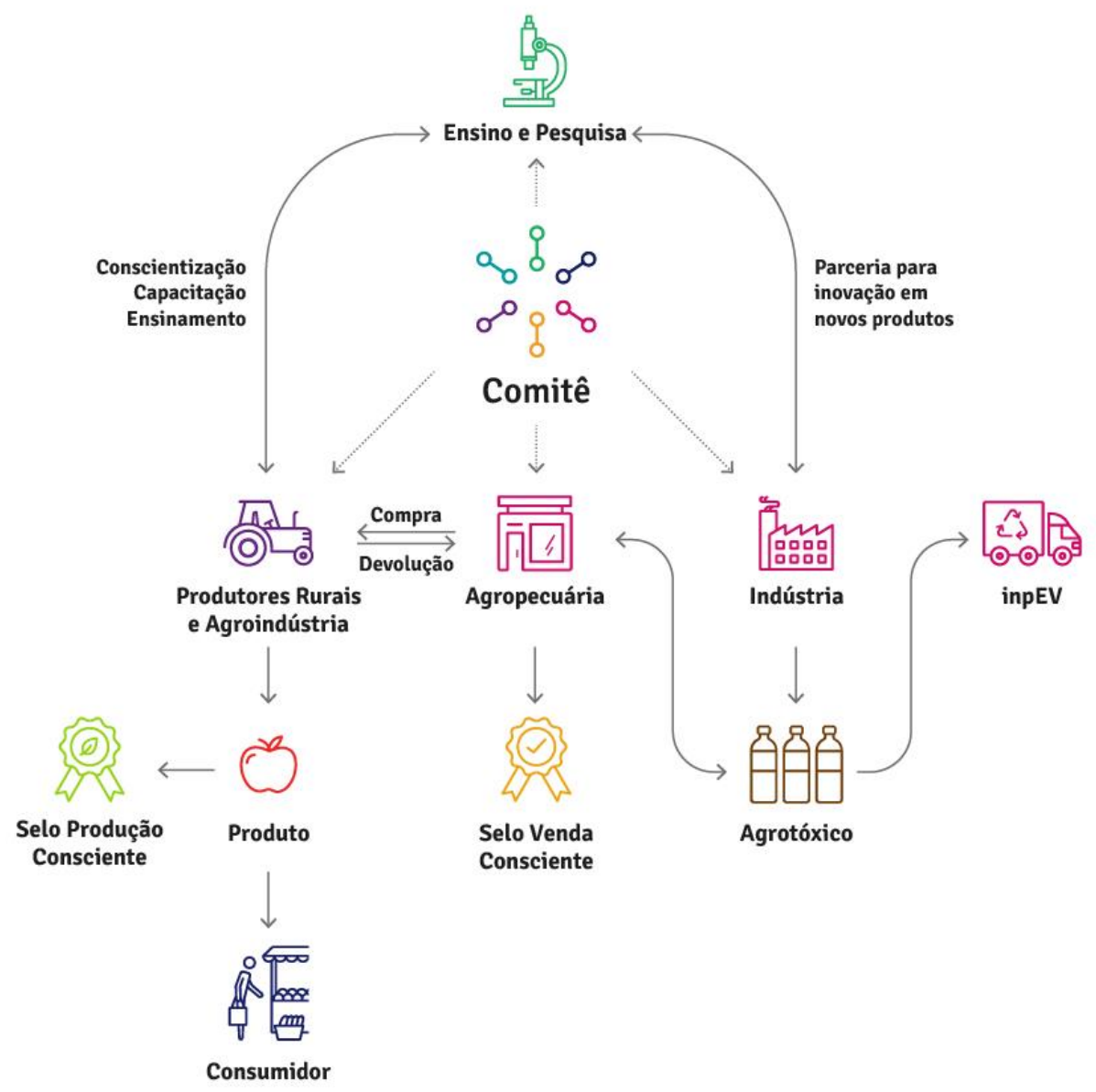

Figura 3 - Esquema do processo e interação dos stakeholder Fonte: Elaborada pelos autores (2018)

Neste modelo de rede, o setor de Ensino e Pesquisa tem seu papel dividido em duas áreas principais: prover informação ao Produtor Rural e à Indústria, ao mesmo tempo que coleta dados para desenvolver pesquisas para novas soluções no âmbito dos agrotóxicos e áreas correlatas. A Indústria, por sua vez, se torna parceira do Ensino e Pesquisa, e atua como um meio de implementação no mercado das pesquisas desenvolvidas em âmbito acadêmico, se beneficiando do caráter de gerar inovação no seu setor. A Agropecuária é fundamental na rede para a venda correta do agrotóxico e serve de conexão entre a Indústria e o Produtor Rural. Portanto, as agropecuárias que fazem parte da rede recebem o Selo Certificador de Venda Consciente e se beneficiam pela chance de fidelização do agricultor participante do comitê. Além disso, é de responsabilidade das agropecuárias retornar as embalagens vazias ao inpEV e, assim, cumprir o ciclo de vida do produto.

Depois que o agricultor participante do comitê recebeu o treinamento adequado, por meio do setor de Ensino e Pesquisa, e adquiriu o produto correto para sua necessidade, ele está apto a cultivar um plantio com a aplicação de agrotóxicos nos níveis adequados. Portanto, para que o consumidor final tenha conhecimento do diferencial, o produto receberá o Selo de Produção Consciente, informando que o alimento foi produzido respeitando os níveis limites de agrotóxicos. Dessa forma, a rede proposta cumpre seu objetivo de oferecer ao mercado um produto mais seguro ao consumidor, ao agricultor e ao meio ambiente, bem como gera um vínculo entre todos os integrantes e cria um processo com benefícios a todos os setores envolvidos, garantindo o engajamento dos mesmos. Os Representantes do Governo participam do comitê para regulamentar as normas e fiscalizar estas ações.

A governança da rede terá o envolvimento dos diversos segmentos da sociedade no plenário, legitimando as ações do comitê e fortalecendo o vínculo deste órgão com o governo e a 
comunidade, tornando-a mais democrática e transparente. O comitê será normatizado pelo Regimento Interno e o plenário é o órgão principal, instituindo, por meio de votação, todas as decisões do comitê, elegendo os membros da Diretoria e as suas competências. O modelo de governança, sugerido para o comitê, é o da organização administrativa da rede, proposto por Provan e Kenis (2008), e que é utilizado no Comitesinos. Recomenda-se que os órgãos do governo e órgãos do sistema não tenham direito a voto e não possam participar como membros da diretoria. $\mathrm{O}$ principal instrumento de gestão do comitê deverá ser a elaboração do planejamento estratégico. Projetos envolvendo a sociedade também serão fundamentais para o reconhecimento da importância do comitê para a sociedade.

\subsubsection{Resultados esperados para a nova rede multi-stakeholders}

A rede demandará uma interação mais dinâmica entre os membros devido ao contexto dos agrotóxicos. A necessidade desta interação se dará em razão dos processos de compra e venda dos produtos pelas indústrias, agropecuária, agricultor, agroindústrias, centros de distribuição de alimentos e com o consumidor final. Os procedimentos de comunicação entre os membros também serão realizados durante as plenárias e pela secretaria executiva e assessor de imprensa. Manter um bom relacionamento com os meios de comunicação é fundamental também para criação de valor perante a sociedade. Os principais resultados da rede serão alcançados pela sistematização dos processos para minimizar os impactos dos agrotóxicos. A rede deverá realizar periodicamente a apresentação dos principais indicadores, a prestação de contas da gestão atual e o demonstrativo dos resultados alcançados.

Envolver a sociedade nos processos de capacitação, será fundamental para o crescimento do comitê (Roloff, 2008; Rocha \& Goldschmidt, 2010). A Figura 4 representa a rede do Comitê para a redução dos impactos dos agrotóxicos.

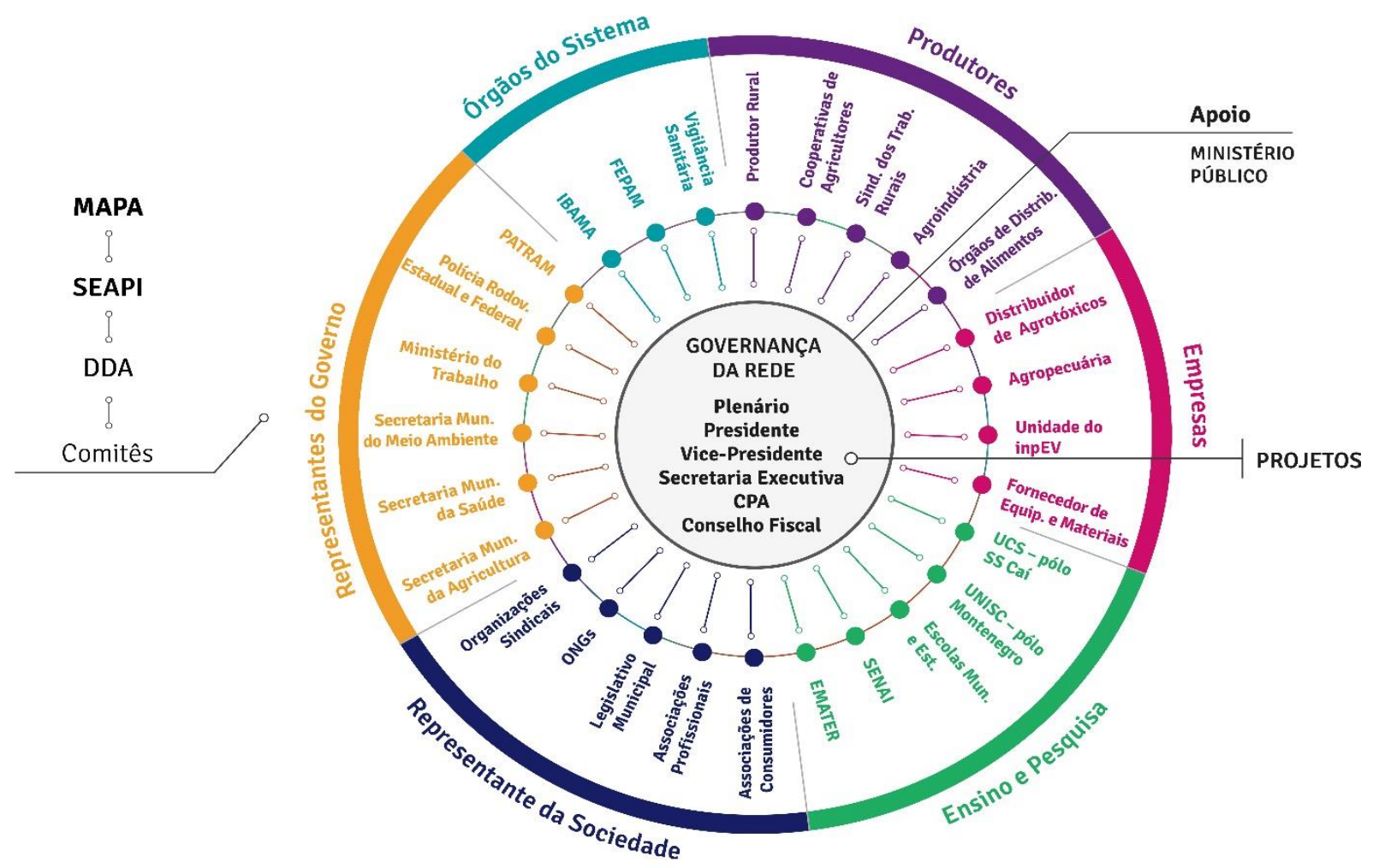

Figura 4 - Representação gráfica do Comitê para redução dos agrotóxicos

Fonte: Elaborada pelos autores (2018) 


\subsubsection{Validação da proposta}

As quatro categorias de stakeholders entrevistadas para a validação da proposta (Órgão estadual de apoio à agricultura (E1), Sindicato dos trabalhadores rurais (E2), Universidade (E3) e Ministério Público (E4)) identificaram, de acordo com a sua percepção, a possibilidade de implementação desta rede e as dificuldades que poderá enfrentar para ser estruturada. Eles também foram questionados sobre os resultados que esta rede poderá alcançar e a sua eficácia para minimizar os problemas relacionados ao uso inadequado dos agrotóxicos na região compreendida pelo Vale do Caí - RS. A proposta da rede foi considerada válida pelos agentes entrevistados. Como sugestão, poderia ser integrada aos comitês de bacia, acrescentando os grupos de stakeholders do contexto dos agrotóxicos, além de posicionar o Ministério Público como órgão fiscalizador.

\subsection{Discussão dos resultados}

A formação de redes colaborativas envolvendo múltiplos stakeholders, vem sendo utilizada para a solução de problemas sociais complexos tanto no Brasil (Calixto, 2009; Harrison, Freeman \& Abreu, 2015; Neutzling, Santos, Barcellos \& Land, 2015) quanto no exterior (Alvarez, Pilbeam \& Wilding, 2010; Airike, Rotter \& Mark-Herbert, 2016; Kilelu, Klerkx \& Leeuwis, 2013). A premissa subjacente é que esse modelo de rede é mais adequado para solucionar problemas ambientais e sociais de maneira mais eficiente do que deixar a tarefa a cargo do Estado porque gera aprendizagem dos envolvidos e soluções alinhadas com suas necessidades (Souza, 2012).

A estruturação de uma nova rede pode se beneficiar de experiências anteriores, tanto bemsucedidas (Alvarez et al., 2010) quanto aquelas que enfrentaram dificuldades (Moog et al, 2015; Saffer et al, 2018). Assim, neste estudo as características do Comitesinos serviram de inspiração para a proposta de uma nova rede, como apresentado na figura 5.

\begin{tabular}{|c|c|c|}
\hline \multirow{2}{*}{$\begin{array}{c}\text { Critérios } \\
\text { analisados }\end{array}$} & COMITESINOS & Rede proposta \\
\hline & Evidências & Proposições \\
\hline $\begin{array}{l}\text { Formação } \\
\text { da rede }\end{array}$ & $\begin{array}{l}\text { Surgiu em resposta a pressão da sociedade } \\
\text { devido a poluição no rio e conflitos quanto } \\
\text { ao uso da água no Rio dos Sinos. }\end{array}$ & $\begin{array}{l}\text { Implantação de uma rede piloto em uma região } \\
\text { específica, como resposta ao uso indiscriminado de } \\
\text { agrotóxicos na agricultura familiar. }\end{array}$ \\
\hline $\begin{array}{l}\text { Composição } \\
\text { da rede }\end{array}$ & $\begin{array}{l}\text { Stakeholders de diversos setores da } \\
\text { sociedade; Divisão em quatro grupos: } 40 \% \\
\text { usuários da água, } 40 \% \text { representantes da } \\
\text { população e } 20 \% \text { divididos entre } \\
\text { representantes do governo e órgãos do } \\
\text { sistema }\end{array}$ & $\begin{array}{l}\text { Organização em seis grupos, organizado de maneira } \\
\text { democrática e não hierárquica: Produção rural, } \\
\text { Empresas, Instituições de Ensino, Representantes } \\
\text { da sociedade, Representantes do governo e Órgãos } \\
\text { do Sistema. }\end{array}$ \\
\hline Governança & $\begin{array}{l}\text { Modelo de governança: Organização } \\
\text { Administrativa da Rede; O plenário é o } \\
\text { órgão principal, elege o Presidente, o } \\
\text { Vice-Presidente, a Secretaria Executiva e } \\
\text { a Comissão Fiscal. Gestão descentralizada } \\
\text { e participativa; Ações baseadas em } \\
\text { estudos técnicos. }\end{array}$ & $\begin{array}{l}\text { Modelo de governança: Organização } \\
\text { Administrativa da Rede. O plenário é o órgão } \\
\text { principal. Ele elege o Presidente, o Vice-Presidente, } \\
\text { a Secretaria Executiva e a Comissão Fiscal; } \\
\text { Mandato dois anos; Gestão descentralizada e } \\
\text { participativa; Ações baseadas em estudos técnicos. }\end{array}$ \\
\hline Dificuldades & $\begin{array}{l}\text { Conflitos de interesses; Dificuldades em } \\
\text { receber do Estado os recursos financeiros } \\
\text { para manter as despesas administrativas; } \\
\text { Os recursos do comitê são escassos; Pouco }\end{array}$ & $\begin{array}{l}\text { Conflitos de interesse; Resistência de algumas } \\
\text { categorias em aceitar mudanças nos processos de } \\
\text { compra, venda e produção dos alimentos; Poderá } \\
\text { encontrar dificuldades em receber recursos do }\end{array}$ \\
\hline
\end{tabular}

Revista de Gestão Social e Ambiental - RGSA, São Paulo, v. 12, n. 1, p. 21-37, jan./abr. 2018. 
A estruturação de redes multi-stakeholders para a solução de problemas sociais complexos

\begin{tabular}{|c|c|c|}
\hline & apoio do Estado para as ações do comitê. & Estado para manter as despesas administrativas. \\
\hline Resultados & $\begin{array}{l}\text { Reconhecimento da força do comitê pela } \\
\text { sociedade e pelos agentes políticos; } \\
\text { Principais indicadores: qualidade e } \\
\text { quantidade da água da bacia, recuperação } \\
\text { da mata ciliar, capacitação em projetos, } \\
\text { presença nas assembleias; Inclusão da } \\
\text { sociedade e dos membros em todos os } \\
\text { projetos do comitê. }\end{array}$ & $\begin{array}{l}\text { Selo de Venda Consciente e Produção Consciente } \\
\text { emitidos pelo comitê; Reconhecimento pela } \\
\text { sociedade da importância do comitê na redução da } \\
\text { contaminação pelos agrotóxicos; Principais } \\
\text { indicadores: redução do uso dos agrotóxicos, } \\
\text { capacitação em projetos, presença nas assembleias; } \\
\text { Inclusão da sociedade nos projetos do comitê. }\end{array}$ \\
\hline
\end{tabular}

Figura 5: Comparação entre as características do Comitesinos e a rede proposta

Fonte: Elaborado pelos autores (2018)

A proposta para a criação da nova rede tem como ponto de partida um problema social complexo que, a exemplo do Comitesinos, necessita da articulação de diversos atores para encaminhar possíveis soluções. A inclusão de seis categorias de atores (Produção Rural, Empresas, Instituições de Ensino, Sociedade, Governo e Órgãos do Sistema) busca garantir que os interesses dessas categorias estejam representados na nova rede. Essa é uma condição indispensável para que as decisões obtenham legitimidade e sejam colocadas em prática, como destacado por Rollof (2008) e Scarlett e McKinney (2016).

A opção por uma governança por meio de Organização Administrativa da Rede (OAR) (Provan \& Kenis, 2008) é adequada para redes com muitos participantes e que precisam de uma estrutura mínima capaz de implementar as decisões. Ao contrário de redes em que há confiança generalizadas entre os participantes, como no caso analisado por Rezende (2014), redes formadas por atores com interesses divergentes e possíveis limitações de confiança terão maiores chances de sucesso utilizando o modelo de OAR (Provan \& Kenis, 2008).

De maneira similar às dificuldades relatadas por Moog et al (2015) e Saffer et al (2018), o Comitesinos precisa lidar com conflitos de interesses entre os participantes. No caso da nova rede proposta, os entrevistados preveem dificuldades relacionadas à aceitação de alguns stakeholders em promover mudanças. Mudanças no padrão estão relacionadas diretamente à resistência dos fabricantes e dos agricultores em reduzir o uso dos agrotóxicos. Neste caso, na concepção dos fabricantes, a venda diminuiria e o agricultor correria riscos de prejudicar a sua lavoura em utilizar o agrotóxico como medida corretiva. Para que haja o engajamento destes stakeholders, será necessário apresentar os benefícios em investir em capacitação e inovação em produtos mais seguros para a agricultura.

O papel da universidade é considerado muito importante para obter legitimidade junto aos produtores. De acordo com os entrevistados E1 e E4, para que um empreendimento dessa natureza tenha sucesso, é necessário que alguma instituição de ensino e pesquisa assuma a iniciativa, evitando que prepondere a questão política. Esse resultado contribui para a discussão sobre a formação de redes multi-stakeholder (Carneiro et al., 2015; Caporal et al., 2005), ao demonstrar que a participação de instituições de pesquisa é relevante para gerar conhecimento técnico, promover a legitimidade da rede e minimizar disputas políticas (Moog et al., 2015).

Para o entrevistado E4, a importância desse modelo de rede está na integração entre as diversas categorias da sociedade e, desta forma, a comunicação fluirá e pode-se chegar a soluções que não se consegue individualmente. O entrevistado E3 comenta que este modelo de rede é importante para minimizar os problemas da sociedade, "[...] este modelo de rede, pra mim, é fundamental que aconteça. Acho que sem isso não se consegue, realmente, encaminhar soluções para os problemas que enfrentamos". Esses resultados reforçam o papel de redes de atores para solucionar problemas complexos, alinhado com os estudos de Alvarez et al. (2010), Airike et al. (2016) e Kilelu et al. (2013). 


\section{CONSIDERAÇÕES FINAIS}

Em relação ao problema de pesquisa que buscava responder como estruturar uma rede de multi-stakeholders para a solução de um problema social complexo e estabelecer seu modelo de governança, a pesquisa convergiu à demanda de Carneiro et al. (2015), Jacobi (2008) e Roloff (2008) ao propor soluções ao uso inadequado de agrotóxicos na agricultura familiar. Fez-se uso de uma iniciativa que envolvesse a coletividade por meio do Comitê para redução dos agrotóxicos, ou seja, de uma rede multi-stakeholder.

Por meio da proposta da nova rede, o estudo atende ao chamado de demonstrar de maneira empírica, tomando por base uma rede consolidada (Comitesinos), como estruturar sistematicamente essa rede, bem como a forma de governança mais adequada para lidar com os objetivos e interesses de múltiplas partes envolvidas em problemas complexos (Klijn, 2014; Harrison et al., 2015; Sandfort \& Milward, 2014). Evidenciou-se na proposta do novo modelo de rede, a forma de governança da organização administrativa da rede (Provan \& Kenis, 2008).

Ademais, se propõe o envolvimento da sociedade nos processos de capacitação, o que será fundamental para o crescimento do Comitê (Roloff, 2008; Rocha \& Goldschmidt, 2010). Cabe salientar que, ao mesmo tempo em que o uso inadequado dos agrotóxicos é um problema social complexo que exige a interação de um grande número de stakeholders com interesses distintos, a análise do caso específico da rede estudada como base, permite gerar novos insights para situações similares em que a mobilização de redes multi-stakeholders se faça necessária.

Aponta-se o tempo como um fator limitador para a segunda etapa da pesquisa, de maneira que se considera importante seguir com a proposta futuramente. Outro limitador foi a carência de estudos relacionados à criação de redes de stakeholders, considerando importante desenvolver estudos relacionados às interações entre as partes interessadas no sentido de desenvolver estruturas em rede para solucionar problemas importantes para a sociedade. Destaca-se que esta proposta poderá ser testada de maneira empírica e também usada como modelo para estruturar outras redes colaborativas com o objetivo de minimizar problemas sociais complexos.

\section{REFERÊNCIAS}

Alvarez, G., Pilbeam, C. \& Wilding, R. (2010). Nestlé Nespresso AAA sustainable quality program: an investigation into the governance dynamics in a multi-stakeholder supply chain network. Supply Chain Management: An International Journal, 15(2),165-182.

Airike, P. E., Rotter, J. P. \& Mark-Herbert, C. (2016). Corporate motives for multi-stakeholder collaboratione corporate social responsibility in the electronics supply chains. Journal of Cleaner Production, 131, 639-648.

Bardin, L. (2010). Análise de conteúdo. Lisboa: Edições 70.

Brass, D. J., Galaskiewicz, J., Greve, H. R. \& Tsai, W. (2004). Taking stock of networks and organizations: a multilevel perspective. Academy of Management Journal, 47(6), 795-817.

Calixto, L. (2009). Evidenciação socioambiental na América Latina: o diálogo com multistakeholders. In Congresso Brasileiro de Custos - Fortaleza, 16.

Caporal, F. R., Costabeber, J. A. \& Paulus, G. (2005). Agroecologia como matriz disciplinar para um novo paradigma de desenvolvimento rural. In Congresso Brasileiro de Agroecologia, Florianópolis, SC, 3. 
Carneiro, F. F., Augusto, L. G. S., Rigotto, R. M., Friedrich, K. \& Búrigo, A. C. (2015). (Org.). Dossiê Abrasco: um alerta sobre os impactos dos agrotóxicos na saúde. Rio de Janeiro: Epsjv; São Paulo: Expressão Popular.

Comitê de Gerenciamento da Bacia Hidrográfica do Rio dos Sinos (Comitesinos). (2016).

Regimento Interno. Recuperado em: 1 jun. 2016, de: 〈http://www.comitesinos.com.br〉.

Corede (2010). Planejamento estratégico do Vale do Caí. (1. ed). São Sebastião do Caí, RS: Gráfica e Livraria Dominó.

Dyer, J. H. \& Singh, H. (1998). The relational view: cooperative strategy and sources of interorganizational competitive advantage. The Academy of Management Review, 23(4), 660-679.

Francisco, R. P. (2011). Gestão de redes de colaboração: conceitos e aplicações. Revista Científica da Unicamp, 4(4), 1-9.

Freeman, R. E. (1984). Strategic management: a stakeholder approach. Boston: Pitman. Fundação de Economia e Estatística do Rio Grande do Sul (FEE). (2016). Painel do agronegócio no Rio Grande do Sul - 2016. Porto Alegre: FEE.

Geremia, B. (2011). Agrotóxico: o emprego indiscriminado de produtos químicos no ambiente de trabalho rural e a responsabilidade por danos à saúde. Dissertação. Programa de Pós-Graduação de Mestrado em Direito. Universidade de Caxias do Sul, Caxias do Sul - RS. Disponível em: < https://repositorio.ucs.br/xmlui/handle/11338/600>. Acesso em: 01 jun. 2016.

Harrison, J. S., Freeman, R. E. \& Abreu, M. C. S. (2015). Stakeholder theory as an ethical approach to effective management: applying the theory to multiple contexts. Review of Business Management, São Paulo, 17(55), 858-869.

Jacobi, P. R. (2008). Governança da água e aprendizagem social no Brasil. Sociedad Hoy, 15, 2544.

Kilelu, C. W., Klerkx, L. \& Leeuwis, C. (2013). Unravelling the role of innovation platforms in supporting co-evolution of innovation: contributions and tensions in a smallholder dairy development programme. Agricultural Systems, 118, 65-77.

Klijn, E.-H. (2014). Redes de política e implementação. Gerenciando interações complexas. In Crooper, S. et al. Handbook de relações interorganizacionais da Oxford (Cap. 5, 108-133). Porto Alegre: Bookman.

Lopes, M. M. C. (2015). A influência dos stakeholders na responsabilidade social empresarial estratégica. Tese de doutoramento. Lisboa: Iscte-IUL, 2015. Recuperado em: 10 mar.2016, de: <http://hdl.handle.net/10071/10038>.

Milagres, R. M., Rezende, O. \& Gonçalves, C. A. (2012). Modelo integrado para análise da governança em redes colaborativas público-privadas. In Encontro da Associação Nacional de Pósgraduação e Pesquisas em Administração, Enanpad, Rio de Janeiro - RJ, 36.

Moog, S., Spicer, A., \& Böhm, S. (2015). The politics of multi-stakeholder initiatives: the crisis of the forest stewardship council. Journal of Business Ethics, 128(3), 469-493. 
Neutzling, D. M., Santos, M. S., Barcellos, M. D. \& Land, A. L. (2015). Value creation from internationalization of sugar cane by-products: a multi-stakeholder view of artisanal cachaça production. Review of Business Management, São Paulo, 17(55), 890-910, Special Edition.

Provan, K. G. \& Kenis, P. (2008). Modes of network governance: structure, management, and effectiveness. Journal of Public Administration Research and Theory, 18(2), 229-252.

Rezende, O. (2014). Governança em rede [manuscrito]: estudo da estrutura relacional no projeto "A Cor da Cultura". Tese de Doutorado. Belo Horizonte.

Rocha, T., Goldschmidt, A. (2010). Gestão dos stakeholders: como gerenciar o relacionamento entre a empresa e seus públicos de interesse. São Paulo. Saraiva.

Roloff, J. (2008). Learning from multi-stakeholder networks: issue-focussed stakeholder management. Journal of Business Ethics, 82, 233-250.

Saffer, A. J., Yang, A., \& Taylor, M. (2018). Reconsidering power in multi-stakeholder relationship management. Management Communication Quarterly, 32(1), 121-139.

Sandfort, J. \& Milward, H. B. (2014). Serviços colaborativos no setor público. In Crooper, S. et al. Handbook de relações interorganizacionais da Oxford. (Cap. 6, 134-158). Porto Alegre: Bookman.

Scarlett, L., \& McKinney, M. (2016). Connecting people and places: the emerging role of network governance in large landscape conservation. Frontiers in Ecology and the Environment, 14(3), 116125.

Souza, F. A. Z. (2012). Desafios e perspectivas da participação social nos conselhos gestores de duas Unidades de Conservação na baixada santista do estado de São Paulo. Tese de Doutorado. Universidade de São Paulo. São Paulo.

Williamson, O. E. (1993). Calculativeness, trust and economic organisation. Journal of Law and Economics, 36, 453-486.

Yin, R. K. (2015). Estudo de caso: planejamento e métodos. (5. ed). Porto Alegre: Bookman.

Data da submissão: 13/05/2017

Data de aceite: 07/12/2017 